University of Nebraska - Lincoln

DigitalCommons@University of Nebraska - Lincoln

U.S. Environmental Protection Agency Papers

U.S. Environmental Protection Agency

2016

\title{
Alpha-lipoic acid supplementation protects enzymes from damage by nitrosative and oxidative stress
}

\author{
Sylvia Hiller \\ University of North Carolina at Chapel Hill \\ Robert DeKroon \\ University of North Carolina at Chapel Hill \\ Eric D. Hamlett \\ Medical University of South Carolina \\ Longquan $\mathrm{Xu}$ \\ University of North Carolina at Chapel Hill \\ Cristina Osorio \\ University of North Carolina at Chapel Hill \\ See next page for additional authors
}

Follow this and additional works at: https://digitalcommons.unl.edu/usepapapers

Part of the Earth Sciences Commons, Environmental Health and Protection Commons, Environmental Monitoring Commons, and the Other Environmental Sciences Commons

Hiller, Sylvia; DeKroon, Robert; Hamlett, Eric D.; Xu, Longquan; Osorio, Cristina; Robinette, Jennifer; Winnik, Witold; Simington, Stephen; Maeda, Nobuyo; Alzate, Oscar; and Yi, Xianwen, "Alpha-lipoic acid supplementation protects enzymes from damage by nitrosative and oxidative stress" (2016). U.S. Environmental Protection Agency Papers. 256.

https://digitalcommons.unl.edu/usepapapers/256

This Article is brought to you for free and open access by the U.S. Environmental Protection Agency at DigitalCommons@University of Nebraska - Lincoln. It has been accepted for inclusion in U.S. Environmental Protection Agency Papers by an authorized administrator of DigitalCommons@University of Nebraska - Lincoln. 


\section{Authors}

Sylvia Hiller, Robert DeKroon, Eric D. Hamlett, Longquan Xu, Cristina Osorio, Jennifer Robinette, Witold Winnik, Stephen Simington, Nobuyo Maeda, Oscar Alzate, and Xianwen Yi 


\title{
Alpha-lipoic acid supplementation protects enzymes from damage by nitrosative and oxidative stress
}

\author{
Sylvia Hiller ${ }^{\mathrm{a}}$, Robert DeKroon ${ }^{\mathrm{b}}$, Eric D. Hamlett ${ }^{\mathrm{c}}$, Longquan $\mathrm{Xu}^{\mathrm{a}}$, Cristina Osorio ${ }^{\mathrm{d}}$, Jennifer Robinette ${ }^{\mathrm{c}, \mathrm{d}}$, \\ Witold Winnik $^{\mathrm{e}}$, Stephen Simington ${ }^{\mathrm{b}}$, Nobuyo Maeda ${ }^{\mathrm{a}}$, Oscar Alzate ${ }^{\mathrm{f}, * *}$, Xianwen Yi ${ }^{\mathrm{a}, *}$ \\ a Department of Pathology and Laboratory Medicine, The University of North Carolina at Chapel Hill, Chapel Hill, NC, United States \\ b Lineberger Comprehensive Cancer Center, The University of North Carolina at Chapel Hill, Chapel Hill, NC, United States \\ c Department of Neurosciences, Medical University of South Carolina, Charleston, SC, United States \\ d Systems Proteomics Center, The University of North Carolina at Chapel Hill, Chapel Hill, NC, United States \\ e Proteomic Research Core Unit, NHEERL, U.S. Environmental Protection Agency, Research Triangle Park, NC, United States \\ ${ }^{\mathrm{f}}$ Texas A\&M Health Science Center, College Station, TX, United States
}

\section{A R T I C L E I N F O}

\section{Article history:}

Received 10 February 2015

Received in revised form 29 August 2015

Accepted 2 September 2015

Available online 4 September 2015

\section{Keywords:}

$\alpha$-Lipoic acid

Antioxidant

Nitric oxide (NO)

Nitrosative stress (NS)

Reactive oxygen species (ROS)

Mitochondria

S-nitrosylation

ATP

\begin{abstract}
A B S T R A C T
Background: S-nitrosylation of mitochondrial enzymes involved in energy transfer under nitrosative stress may result in ATP deficiency. We investigated whether $\alpha$-lipoic acid, a powerful antioxidant, could alleviate nitrosative stress by regulating $S$-nitrosylation, which could result in retaining the mitochondrial enzyme activity. Methods: In this study, we have identified the $S$-nitrosylated forms of subunit 1 of dihydrolipoyllysine succinyltransferase (complex III), and subunit 2 of the $\alpha$-ketoglutarate dehydrogenase complex by implementing a fluorescence-based differential quantitative proteomics method.

Results: We found that the activities of these two mitochondrial enzymes were partially but reversibly inhibited by $S$-nitrosylation in cultured endothelial cells, and that their activities were partially restored by supplementation of $\alpha$-lipoic acid. We show that protein $S$-nitrosylation affects the activity of mitochondrial enzymes that are central to energy supply, and that $\alpha$-lipoic acid protects mitochondrial enzymes by altering $S$-nitrosylation levels. Conclusions: Inhibiting protein $S$-nitrosylation with $\alpha$-lipoic acid seems to be a protective mechanism against nitrosative stress.

General significance: Identification and characterization of these new protein targets should contribute to expanding the therapeutic power of $\alpha$-lipoic acid and to a better understanding of the underlying antioxidant mechanisms.
\end{abstract}

(C) 2015 Elsevier B.V. All rights reserved.

\section{Introduction}

Nitric oxide (NO) is a soluble and highly diffusible gas generated by a wide variety of cell types including vascular endothelial cells. NO plays an important role in endothelium-derived smooth muscle relaxation [1]. Excess production of endogenous NO under inflammatory conditions can be toxic to vascular endothelial cells [2]. Unregulated NO production leads to an increase in Reactive Nitrogen Species (RNS) resulting in nitrosative stress (NS), which may give rise to significant pathological outcomes including cellular injury and disease [3]. Specifically, NS is involved in the pathogenesis of low-grade chronic inflammatory-associated diseases such as atherosclerosis and type 2

\footnotetext{
* Correspondence to: X. Yi, Department of Pathology and Laboratory Medicine, The University of North Carolina at Chapel Hill, 710 Brinkhous-Bullitt Building, Chapel Hill, NC 27599-7525, United States.

** Correspondence to: O. Alzate, Texas A\&M Health Science Center, ILSB 1155, 301 Old Main Dr., College Station, TX 77845, United States. (X. Yi).
}

diabetes [4,5]. A better understanding of NS-associated underlying mechanisms may help improve therapeutic outcomes for these diseases.

Evidence shows that NO regulates protein function via S-nitrosylation, a reversible redox post-translational modification that adds an NO group to a reactive cysteine residue in regulatory proteins [6]. In recent years, protein $S$-nitrosylation has received much attention as an ubiquitous regulatory strategy for multiple biological processes [7,8,9]. NO-induced protein $S$-nitrosylation results in the modulation of active-site thiol and disulfide formation that could either inhibit or enhance the catalytic activity of redox-sensitive enzymes [10]. Some investigations have suggested that $S$-nitrosylation is involved in both normal and abnormal vascular function [6], including regulation of key metabolic pathways [11].

Endothelial cells form the inner cellular lining of blood vessels and play a key role in regulating vascular cellular homeostasis, vascular integrity, vasorelaxation, and local inflammation [12]. Dysfunction of the endothelium may result in pathogenic processes associated with a number of cardiovascular diseases such as atherosclerosis, hypertension, heart attack and stroke [13]. Because the endothelium constitutively expresses endothelial nitric oxide synthase (eNOS) and is exposed to NO 
derived from the inducible nitric oxide synthase (iNOS) isoform under inflammatory conditions [14]. NO increase has been found to coincide with an increase in protein $S$-nitrosylation, so it is an ideal tissue for studying $S$ nitrosylation-dependent signals [15]. It is thought that the endogenous production of NO in the endothelium is not sufficient to inhibit endothelial cell activation during inflammation, and that higher concentrations of NO derived from the use of an exogenous NO donor, DETA-NONOate, is required for inducing higher levels of protein $S$-nitrosylation [16].

$\alpha$-Lipoic acid (1,2-dithiolane-3-pentanoic acid; LA) is a di-thiol antioxidant with diverse functions such as RNS quenching, antiinflammatory activity [17], and may be therapeutic in mitochondriarelated disorders $[18,19]$. LA is also a cofactor for several enzymes including pyruvate dehydrogenase complex (PDC) and $\alpha$-ketoglutarate dehydrogenase complex (KDC), two mitochondrial enzymes involved in glucose metabolism and energy production. In a previous study, we reported that endogenous LA production is necessary for mouse embryo survival [20]. This result led us to propose that in addition to its antioxidant capacity, LA is essential for the maintenance of normal levels of energy metabolism [20]. We also found that LA increased the mitochondrial antioxidant capacity, and partially restored mitochondrial enzyme activity and increased ATP yield during sepsis in which an excess of NO had been produced [21]. Other investigators have also reported that the exposure of endothelial cells to small molecular $S$-nitrosothiols significantly down-regulates their mitochondrial function [22]. Therefore, we hypothesized that inflammation-induced excess NO production increases protein $S$-nitrosylation, which may result in diminished oxidative phosphorylation and decreased energy production in some mitochondrial enzymes. We propose that LA is able to alleviate mitochondrial dysfunction by regulating protein $S$-nitrosylation, thus helping cells to retain their energy supply. In this study, we found that through alteration of protein S-nitrosylation, LA partially restores mitochondrial oxidative phosphorylation reserve capacity and ATP production. These findings shed light on a novel mechanism by which LA is able to rescue energy deficiency in inflammation-associated diseases, including low-grade chronic inflammation diseases, such as atherosclerosis and type 2 diabetes.

\section{Materials and methods}

All animal protocols were reviewed and approved by the Ethics Committee of the University of North Carolina at Chapel Hill (Protocol number: 13-208-0).

\subsection{Reagents}

(Z)-1-[2-(2-aminoethyl)- $\mathrm{N}$-(2-ammonioethyl) amino] diazen-1ium-1,2-diolate (DETA-NONOate) was obtained from Cayman Chemical (Ann Arbor, MI). Protease inhibitor cocktail (Complete ${ }^{\mathrm{TM}}$ Mini EDTAfree protease inhibitor cocktail) was from Roche Applied Science (Indianapolis, IN). Antimycin A, coenzyme A, cytochrome C, ferricytochrome $\mathrm{C}$, carbonylcyanide $p$-triflouromethoxyphenyl-hydrazone (FCCP), oligomycin, potassium cyanide, S-methyl methanethiosulfonate (MMTS), rotenone, thiamine pyrophosphate, urea, CHAPS, neocuproine and cuprizone were all from Sigma-Aldrich (St. Louis, MO). Decylubiquinol was from Santa Cruz Biotechnology, Inc. (Dallas, TX); and $\mathrm{R}(+) \alpha$-lipoic acid (LA) was from Toronto Chemical Research (Toronto, Canada). NHS-Cy dyes and dye maleimides were from GE Healthcare (Piscataway, NJ).

\subsection{Cell cultures}

Primary aortic endothelial cells from C57BL/6J mice (Cell Biologics, Chicago, IL) and mouse brain endothelioma cells (bEnd.3, American Type Culture Collection, Manassas, VA) were used in these studies. The latter, an alternative source of endothelial cells, was used to compare the possible different responses to NS between the primary cells and the cell line. The primary cells and the brain cells were cultured in Complete Mouse Endothelial Cell Medium (Cell Biologics), and in Dulbecco's Modified Eagle Medium (DMEM) containing 10\% fetal bovine serum (Gibco, Langley, OK), respectively. Both cell types were maintained in a humidified incubator gassed with $5 \% \mathrm{CO}_{2}, 95 \%$ air at $37{ }^{\circ} \mathrm{C}$. LA was dissolved in $100 \mathrm{mM}$ phosphate buffer ( $\mathrm{pH} 7.2$ ) after being converted into LA sodium salt. A concentration of $50 \mu \mathrm{M}$ of LA shows effective protection against oxidative stress in cell cultures [23-25]. Preparation of DETA-NONOate was based on the method by Dranka et al. [26], in which an appropriate dose to induce NS in endothelial cells $(\sim 250 \mu \mathrm{M})$ was established. The amount of NO from DETA-NONOate was released at a constant rate $(\sim 150 \mathrm{nM} / \mathrm{min})$ during the first $8 \mathrm{~h}$, and was monitored by absorbance spectroscopy. This concentration of DETA-NONOate is capable of decreasing the oxygen consumption rate (OCR) [26]. Therefore, this is the concentration that we used for cell treatments in this study. Cell counting was performed using a Neubauer chamber, and the number of dead cells was determined by trypan-blue exclusion before and after treatment. The analysis was performed with 4 groups, 5 samples per group, which were created as follows from cell cultures grown to $\sim 60 \%$ confluence: group 1 : untreated cells (control group); group 2: cells in regular medium for $6 \mathrm{~h}$ followed by treatment with LA for $12 \mathrm{~h}$ (LA group); group 3: cells treated with DETA-NONOate for $6 \mathrm{~h}$ from time zero and then changed to fresh medium for $12 \mathrm{~h}$ (NO group); and group 4: cells treated with DETA-NONOate for $6 \mathrm{~h}$, followed by a change to an LA-containing medium for $12 \mathrm{~h}$ (NO + LA group).

\subsection{Mitochondrial isolation and purity examination}

Mitochondria were isolated from aortic endothelial cells using a Mitochondria Isolation Kit for cultured cells, the reagent-based method (Thermo Fisher Scientific, Rockford, IL, Product No. 89874) following the manufacturer's instructions. Certain critical points of purification procedure provided by other optimized protocols were applicable to our purification $[27,28]$. Harvested cells were homogenized in ice-cold isolation buffer (100 mM Tris-MOPS, $10 \mathrm{mM}$ EGTA/Tris, $200 \mathrm{mM}$ sucrose, $\mathrm{pH} 7.4$ ). The homogenate was centrifuged for $10 \mathrm{~min}$ at $3000 \times g$ at $4{ }^{\circ} \mathrm{C}$. The supernatants were collected in isolation buffer, and then centrifuged for $10 \mathrm{~min}$ at $10,000 \times \mathrm{g}$ at $4{ }^{\circ} \mathrm{C}$. The resulting pellets were re-suspended in $\sim 1 \mathrm{~mL}$ isolation buffer, kept on ice and used within $4 \mathrm{~h}$ or stored at $-80^{\circ} \mathrm{C}$ for later use.

The purity of the isolated mitochondria compared to cytosolic fractions was assessed via Western blot analysis for HSP60 or Tubulin and quantitated using Image Studio Light software (LICOR Biotechnologies, Lincoln, Nebraska). Protein concentrations were measured using the Thermo Scientific ${ }^{\mathrm{TM}}$ BCA Protein Assay Kit (Product No. 23,225). A total of $20 \mu \mathrm{g}$ of cytosolic proteins and $18.8 \mu \mathrm{g}$ of mitochondrial proteins (the different loading amounts were normalized during quantitative calculation afterwards) were loaded on $12 \% \mathrm{kD}^{\mathrm{TM}}$ Mini-PROTEAN® $\mathrm{TGX}^{\mathrm{TM}}$ Precast gels (BioRad, Hercules, CA) and transferred onto nitrocellulose membranes. Membranes were blocked with 4\% BSA for $1 \mathrm{~h}$. Proteins were detected with anti-HSP60 (Rabbit polyclonal, 1:10,000, Abcam Cat\# AB46798) and anti-tubulin (Mouse monoclonal antitubulin, beta III isoform, Chemicon Cat\# MAB 1637), followed by secondary horseradish peroxidase (HRP)-conjugated antibody, either rabbit $\operatorname{IgG}(1: 500)$ or mouse IgG (1:500), from Jackson ImmunoResearch Laboratories, Inc. (West Grove, PA). Signals were detected with a chemiluminescence detection kit (Millipore).

\subsection{Determination of mitochondrial levels of antioxidant and oxidative stress}

Isolated mitochondria prepared as described above were deproteinated with $5 \%$ trichloroacetic acid. The level of reduced glutathione (GSH), a major endogenous antioxidant in mitochondria, was determined with a Glutathione Assay Kit from Cayman Chemical. The protein concentration of each sample was determined using a bicinchoninic acid assay (BCA; 
Thermo Fisher Scientific). Mitochondrion oxidative stress was measured using 4-Hydroxynonenal (4-HNE) assay kit in accordance with manufacturer's specifications (Cell Biolabs, Inc. San Diego, CA).

Mitochondrial nitrate/nitrite (NOx) levels, as the stable metabolic end products of NO, were determined using a colorimetric assay kit (Cayman Chemical). The absorbance was read on a Biotek Synergy HT Multi-Mode microplate reader (Winooski, VT, USA) using a wavelength of $540 \mathrm{~nm}$. Protein carbonyl content was assessed by using an OxiSelect Protein Carbonyl ELISA kit according to the manufacturer's instructions (Cell Biolabs, Inc.).

\subsection{Determination of ATP production}

ATP generation in the DETA-NONOate-treated primary aortic endothelial cells was analyzed by a luciferase substrate assay (Invitrogen, Carlsbad, CA). Briefly, the cells were homogenized and sonicated in ATP Assay Buffer provided by the company. After centrifugation at $12,000 \times \mathrm{g}$ for $5 \mathrm{~min}$ at $4{ }^{\circ} \mathrm{C}$, the supernatant was removed and used for ATP measurement in an Orion Microplate Luminometer (Berthold Detection Systems, Titertek Instruments, Inc., Huntsville, AL). The amount of ATP was normalized to the protein concentration as determined by the BCA method.

2.6. Measurement of the oxygen consumption rate (OCR) and the extracellular acidification rate (ECAR)

OCR and ECAR were measured using the XF24 extracellular flux analyzer (Seahorse Bioscience, Billerica, MA) following the manufacturers' instructions. Briefly, primary aortic endothelial cells were seeded at a density of $5 \times 10^{4}$ cells per well, treated with $250 \mu \mathrm{M}$ DETANONOate, followed by $50 \mu \mathrm{M}$ LA. The cells were washed with PBS and incubated with bicarbonate-free (no buffering capacity) DMEM at $37^{\circ} \mathrm{C}$ for $1 \mathrm{~h}$. Measurements were taken sequentially, as the cells were incubated, with the following chemicals: (1) oligomycin $(5 \mu \mathrm{g} / \mathrm{mL}), \mathrm{a}$ reversible inhibitor of ATP synthase; (2) FCCP (5 $\mu \mathrm{M})$, an electron uncoupler of ATP synthesis; and (3) antimycin A ( $40 \mu \mathrm{M})$, a complex III inhibitor. Basal levels of OCR and ECAR were obtained in the cultured cells without the additives.

\subsection{Proteomic analysis}

Confluent cells were washed four times with cold PBS, re-suspended in $500 \mu \mathrm{L}$ of cold PBS supplemented with Complete ${ }^{\mathrm{TM}}$ protease inhibitor cocktail without EDTA, and spun at $2000 \times \mathrm{g}$ for $20 \mathrm{~min}$ at $4{ }^{\circ} \mathrm{C}$. Pelleted cells were re-suspended in $500 \mu \mathrm{L}$ lysis buffer ( $8 \mathrm{M}$ urea, $4 \%$ CHAPS, $30 \mathrm{mM}$ Tris, $\mathrm{pH}$ 8.5) supplemented with protease inhibitor cocktail, and then sonicated on ice three times, for $20 \mathrm{~s}$ each with $10 \mathrm{~s}$ rest. After centrifugation, the resulting supernatants were cleaned up using a 2D Clean-Up kit (GE Healthcare), according to the manufacturer's instructions. The final pellet was re-suspended either in lysis buffer or S-nitrosylated-labeling buffer (8 M urea, 4\% CHAPS, $20 \mathrm{mM}$ Tris, $\mathrm{pH} 7.3$ ) and the protein concentration was determined using a 2D Quant kit (GE Healthcare) as instructed by the manufacturer.

A modified fluorescence-switch method [29] was used to detect $S$-nitrosylated proteins as follows. Protein samples were re-suspended in $S$-nitrosylation-labeling buffer, MMTS was added to $100 \mu \mathrm{g}$ of protein sample to produce a final concentration of $20 \mathrm{mM}$ MMTS, and then incubated at room temperature for $1 \mathrm{~h}$ while being protected from light. The samples were cleaned up as previously described [30] to remove unbound MMTS. Then the samples were re-suspended in $S$-nitrosylation-labeling buffer, and finally ascorbic acid was added to a final concentration of $100 \mathrm{mM}$ (Fig. 1). Samples were cleaned again and the resulting pellets were re-suspended in $S$-nitrosylation-labeling buffer, followed by the addition of 500 pmol of Cy5-maleimide and flushed with nitrogen to decrease the possibility of protein oxidation. Samples were incubated at room temperature for $2 \mathrm{~h}$ followed by incubation overnight at $4{ }^{\circ} \mathrm{C}$, protected from light.

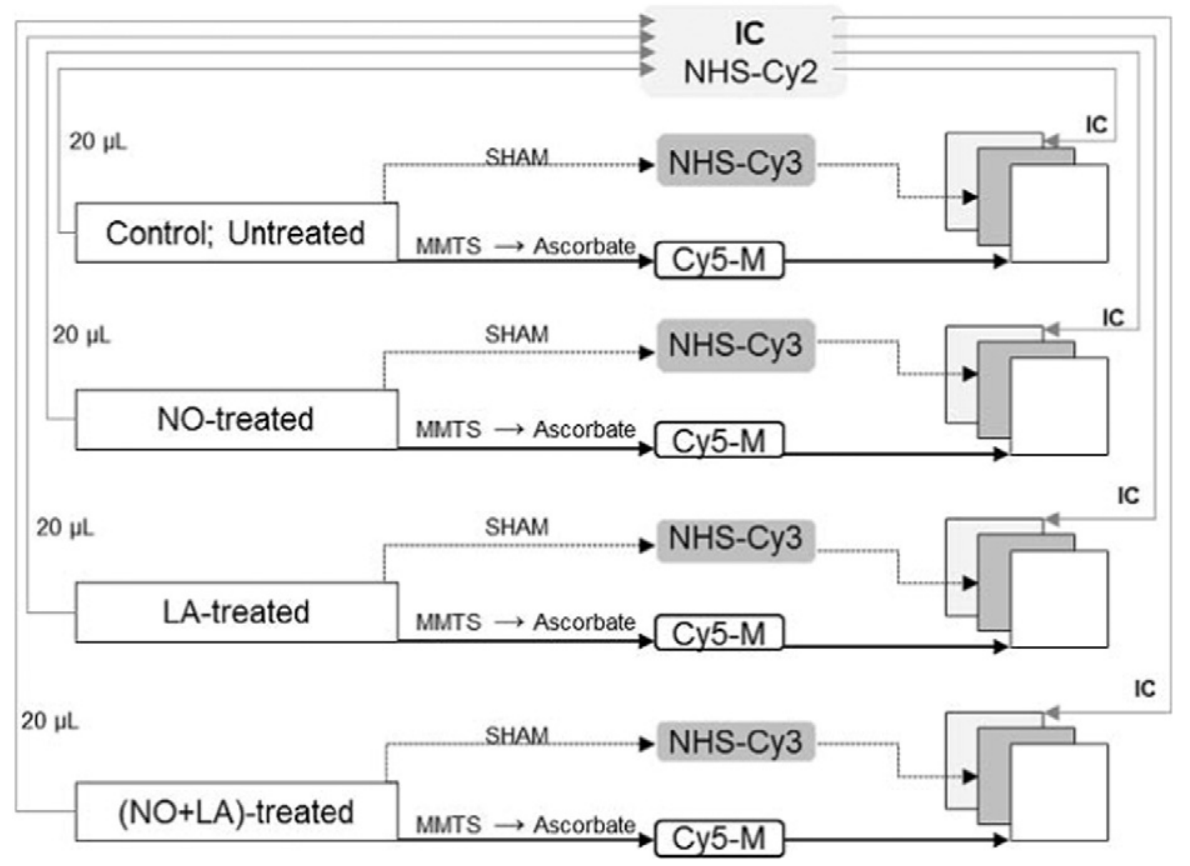

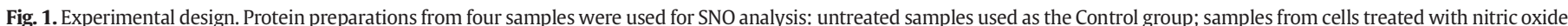

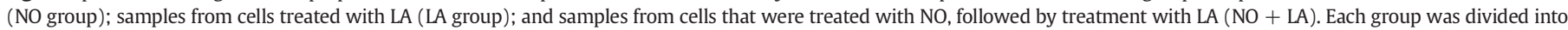

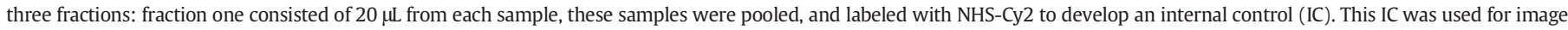

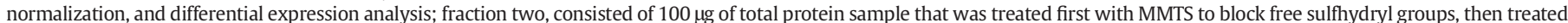

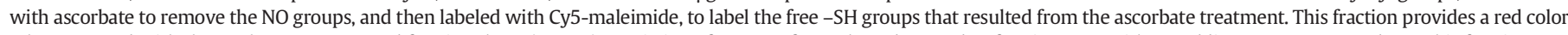

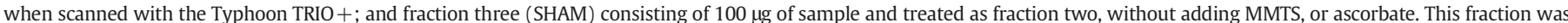

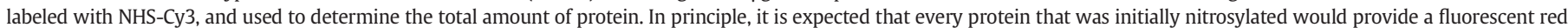

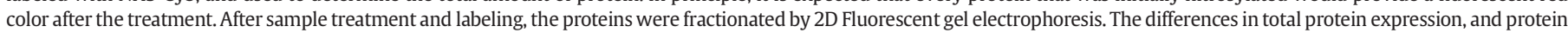
nitrosylation were determined with the Decyder 2D software \{DeKroon et al., 2011-Ref. 29\}. 
An internal control (IC) was prepared by pooling equal amounts of protein $(20 \mu \mathrm{g})$ from all control samples, which were labeled with $400 \mathrm{pmol} / 50 \mu \mathrm{g}$ protein of NHS-Cy2. Aliquots from the IC were added to each gel. A $100 \mu \mathrm{g}$ aliquot of each sample was processed as the $S$-nitrosylation sample without adding either MMTS or ascorbate. After clean-up, these samples were labeled with 400 pmol of NHS-Cy3 to determine total protein expression changes. The labeling reactions were carried out on ice for $30 \mathrm{~min}$, protected from light. To quench the reaction, $1 \mu \mathrm{L}$ of $10 \mathrm{mM}$ lysine was added, and the reaction was incubated for an additional 10 min on ice in the dark. After labeling, corresponding samples were combined as shown in Fig. 1. An equal volume of $2 \times$ sample buffer (8 M urea, 4\% CHAPS, $20 \mathrm{mg} / \mathrm{mL}$ DTT, 2\% ( $v / v)$ IPG buffer 4-7 (GE Healthcare)) was added and the mixture was placed on ice for $15 \mathrm{~min}$. Rehydration buffer ( $8 \mathrm{M}$ urea, 4\% CHAPS, $2 \mathrm{mg} / \mathrm{mL}$ DTT, 1\% ( $v / v$ ) IPG buffer $4-7$ ) was added to a final volume of $250 \mu \mathrm{L}$.

\subsection{Differential fluorescence 2D gel electrophoresis and image analysis}

Differential fluorescence 2D gel electrophoresis was carried out as reported previously [31]. After electrophoresis, the gels were scanned with a Typhoon Trio + (GE Healthcare). Gel images were analyzed as described [31] with Decyder 2D software Ver7.0 (GE Healthcare). The resulting images for $S$-nitrosylated proteins and total protein differential expression were analyzed separately, using the same internal control because the nitrosylated proteins within each group were assigned unique spot numbers, and the "total" protein spot numbers very often do not correlate to the same protein spot [31] due to the isoelectric point shift resulting from the different labels. Spot maps for each gel image (individual samples and internal control) were matched and an ANOVA (SAS Institute Inc., Cary, NC) comparison was performed between Control, LA, $\mathrm{NO}$, and (NO + LA) for each spot. The extended data analysis (EDA) component of DeCyder 7.0 was used for principal component analysis (PCA) and hierarchical cluster analysis (HCA).

\subsection{Protein identification by mass spectrometry (MS)}

For protein identification purposes, approximately $400 \mu \mathrm{g}$ of total protein consisting of equal contributions from each experimental group was separated by 2D gel electrophoresis for spot picking. Matching protein spots between the pick gel and the analytical gels were picked using an Ettan spot picker (GE Healthcare), and digested with trypsin as previously described [32]. Proteins were identified using a 4800 MALDI TOF/TOF (Applied Biosystems (AB), Foster City, CA) mass spectrometer either at the UNC Proteomics Core Facility or the US EPA NHEERL Proteomics Research Core Facility. Mascot software (http://www.matrixscience.com/) was used to identify the proteins from background-subtracted MALDIMS and MS/MS data. MALDI-MS acquisition was followed by MALDIMS/MS peptide sequencing, and the final protein identification was obtained using Protein Pilot 3.0 software (AB SCIEX, Framingham, MA), searching against the mouse (Mus musculus) sub-database of the SwissProt protein database (http://expasy.org/sprot/). Mass-selected MALDI-MS/MS spectra acquisition was performed to increase the protein sequence coverage. The reported proteins were identified based on at least two high-quality (95-99\% peptide confidence scores in Protein Pilot) peptide sequence identifications made from the MS/MS data [32].

\subsection{Alpha-ketoglutarate dehydrogenase (KDC) and complex III activities} in mitochondria

KDC activity in isolated mitochondria was determined by monitoring the reduction of $\mathrm{NAD}^{+}$at $340 \mathrm{~nm}$. Briefly, isolated mitochondria were resuspended in buffer containing $25 \mathrm{mM} \mathrm{KH}_{2} \mathrm{PO}_{4}, 5 \mathrm{mM} \mathrm{MgCl}$, $0.5 \mathrm{mM}$ EDTA, 0.1\% $(v / v)$ Triton X-100, $40 \mathrm{mM}$ rotenone, $1.0 \mathrm{mM}$ $\mathrm{NAD}^{+}, 0.2 \mathrm{mM}$ thiamin pyrophosphate, and $0.1 \mathrm{mM}$ Coenzyme A, $\mathrm{pH}$ 7. The mitochondria were sonicated in a water bath at room temperature for $30 \mathrm{~s}$. A reaction mixture containing $5 \mathrm{mM} \mathrm{MgCl}_{2}, 40 \mathrm{mM}$ rotenone, $0.1 \mathrm{mM}$ Coenzyme $\mathrm{A}, 0.2 \mathrm{mM}$ thiamine pyrophosphate and $1 \mathrm{mM} \mathrm{NAD}^{+}$were added to the mitochondrial medium to reach a final concentration of $0.4 \mathrm{mg}$ mitochondrial protein $/ \mathrm{mL}$. The reaction was initiated by the addition of $2.5 \mathrm{mM} \alpha$-ketoglutarate [33]. Complex III (ubiquinol-ferricytochrome C oxidoreductase; EC 1.10.2.2) activity in mitochondria was measured by following the increase in absorbance at $550 \mathrm{~nm}$ due to the reduction of ferricytochrome $\mathrm{C}$ [34]. The reaction mixture consisted of $25 \mathrm{mM} \mathrm{KH}_{2} \mathrm{PO}_{4}, \mathrm{pH} 7.4,5 \mathrm{mM} \mathrm{MgCl}$, $2 \mathrm{mM} \mathrm{KCN}$, $2.5 \mathrm{mg}$ bovine serum albumin, $50 \mu \mathrm{M}$ cytochrome $\mathrm{C}$, and $4 \mathrm{mg}$ rotenone.
A

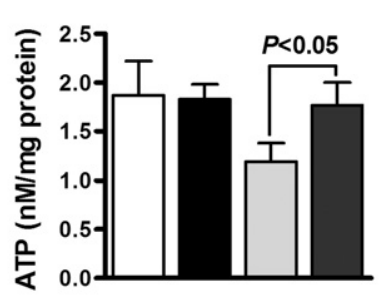

D

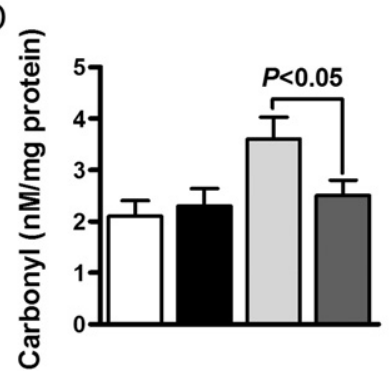

B

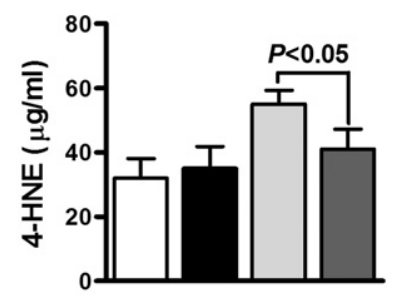

E

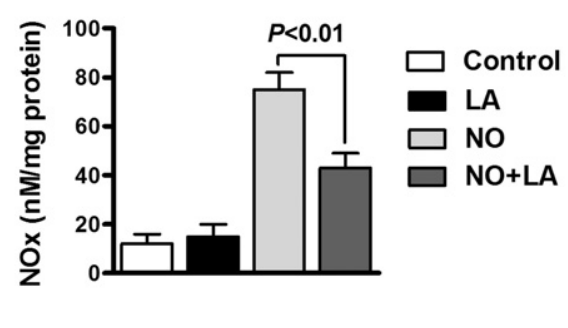

C

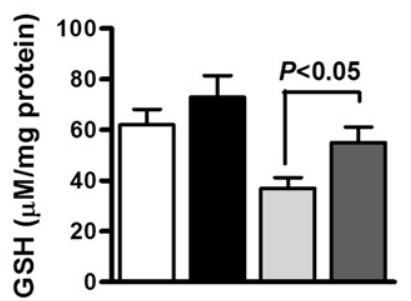

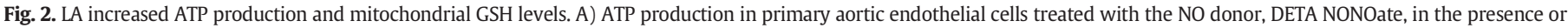

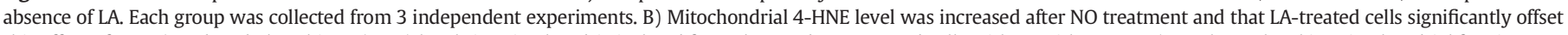

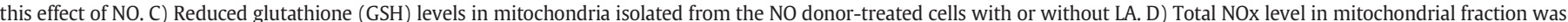

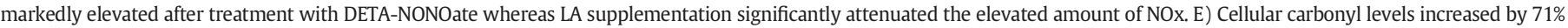

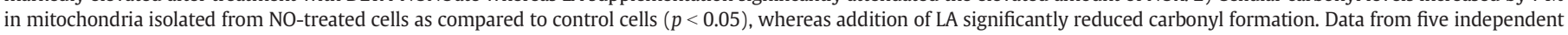
experiments are expressed as the mean \pm SEM. 
A

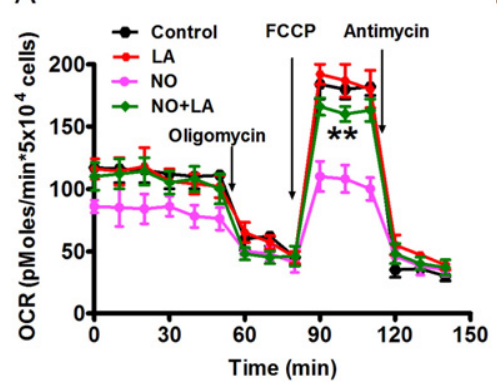

B

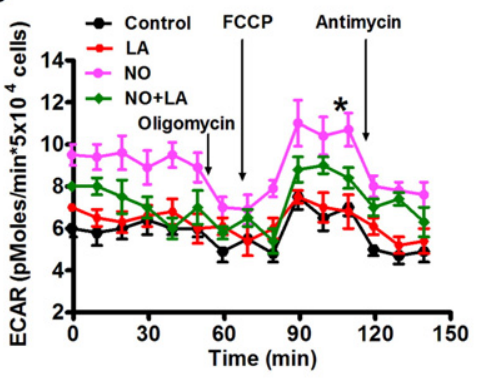

C

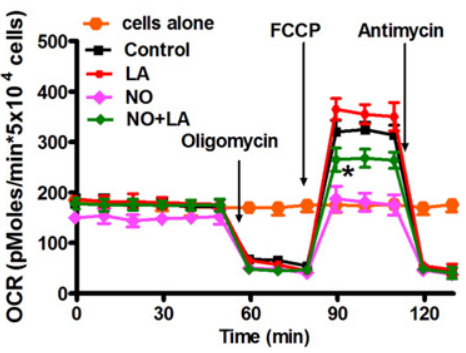

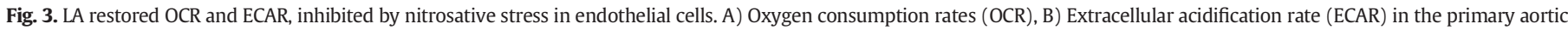

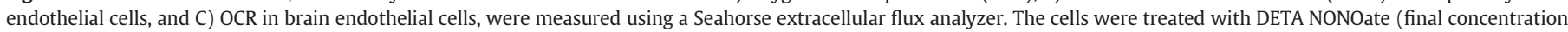

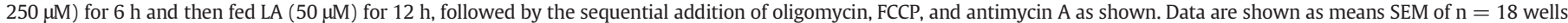
(each group) collected from 3 independent experiments. The OCR and ECAR values are normalized by cell numbers.

Mitochondrial protein $(25 \mu \mathrm{g})$ was added and the reaction was initiated by the addition of $60 \mu \mathrm{M}$ decylubiquinol, and the change in absorbance was monitored for $2 \mathrm{~min}$. To determine antimycin-insensitive activity, the assay was repeated by adding $5 \mu \mathrm{g}$ antimycin $\mathrm{A}$ to the reaction mixture. Antimycin A-sensitive complex III activity was calculated by comparing the resulting values with the initial rate, which was used as the base value. Enzyme activity was expressed as nmole of reduced cytochrome $\mathrm{C}$ per minute per $\mathrm{mg}$ of protein.

\subsection{Statistical analysis}

All data are reported as mean \pm standard error of the mean (SEM). Values of $p<0.05$ were considered to be statistically significant (95\% confidence limits). The significance of the effects of NO, LA, NO + LA and non-treated control groups was compared using one-way ANOVA.

\section{Results}

\subsection{Effect of LA on ATP production, mitochondrial function and redox status}

We measured ATP levels in endothelial cells to determine the effect of excess NO on ATP production. We found that after treatment with DETA-NONOate ATP production decreased by $36 \%$ compared to control cells and that LA supplementation significantly restored ATP levels (Fig. 2A); it is worth noting that LA alone did not affect ATP levels (Fig. 2A). We measured 4-HNE and GSH concentrations in the mitochondria to evaluate whether or not administration of LA alters oxidative stress and can compensate for possible loss of mitochondrial antioxidant capacity due to RNS. Our results show that the mitochondrial 4-HNE level increased by $57 \%$ whereas GSH decreased by 40\% after NO treatment $(p<0.01)$ and that LA-treated cells are less effected by NO. While LA alone did not significantly reduce 4-HNE and increase GSH levels without DETA-NONOate treatment, it suggests that the major
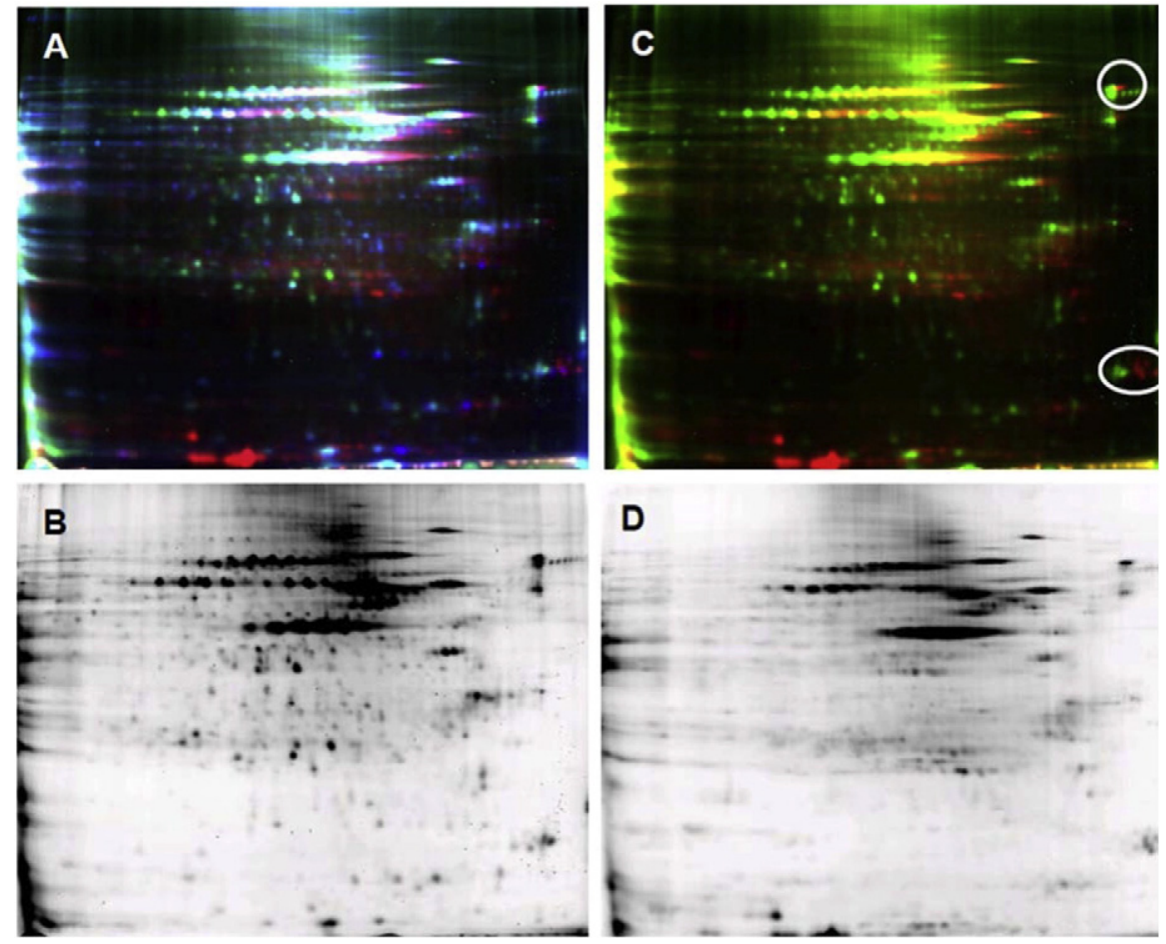

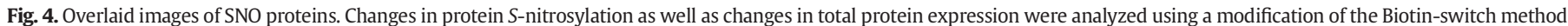

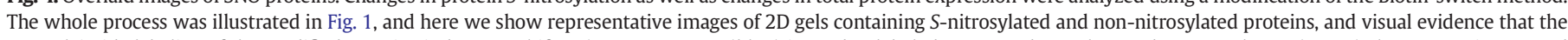

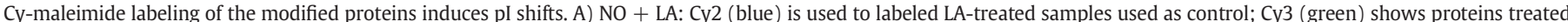

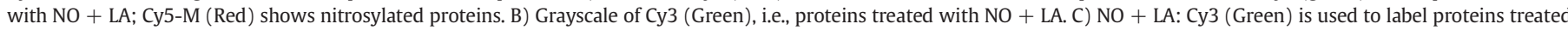

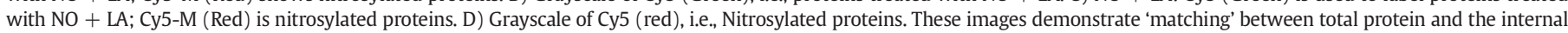
control, while Cy5-M produces a shift in isoelectric point as exemplified by the spots in oval. 
A

S-Nitrosylated Proteins

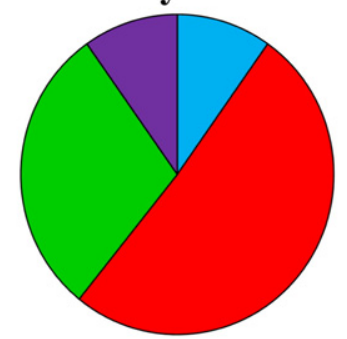

$\square$ Other, $5(10 \%)$

LA Only, 26 (51\%)

No effect altered by LA, 15 (29\%)

No effect not altered by LA, 5 $(10 \%)$
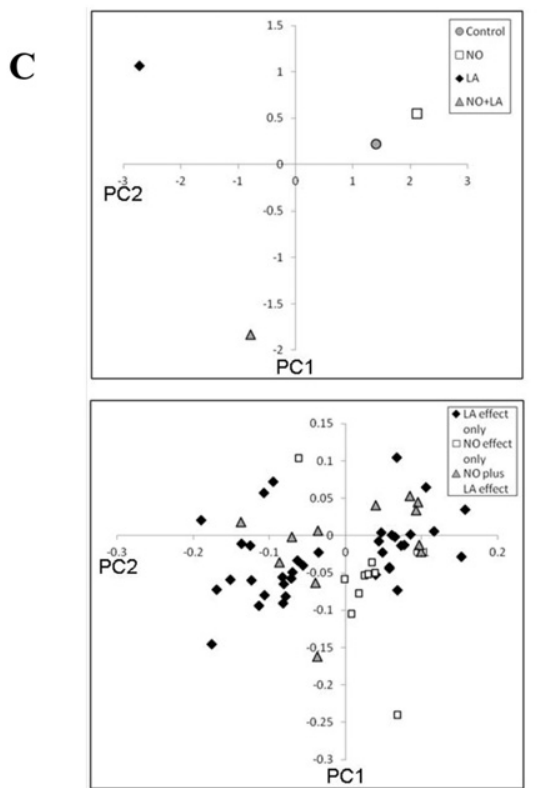

B

Total Protein Expression Changes

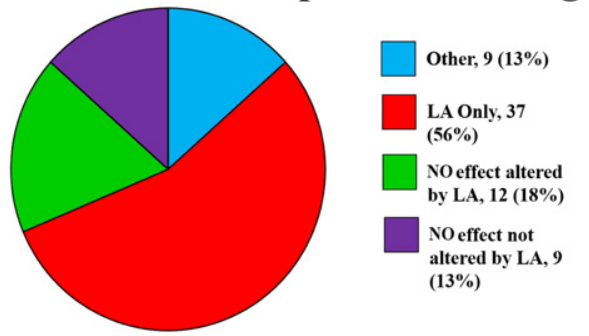

D

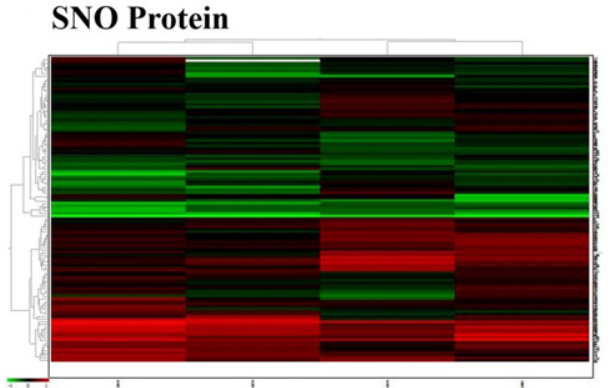

Total Protein

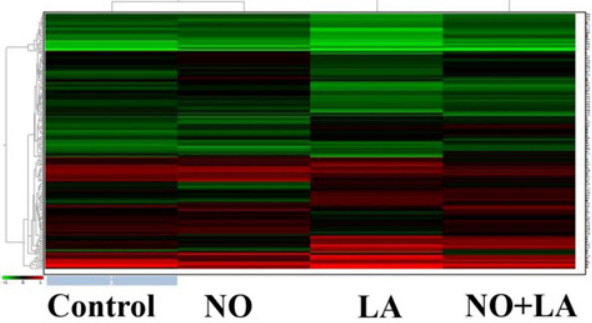

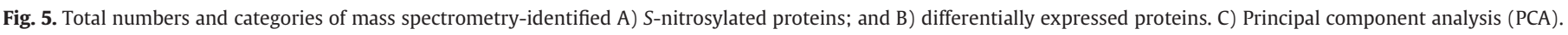

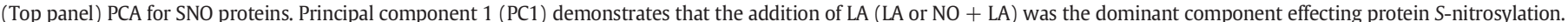

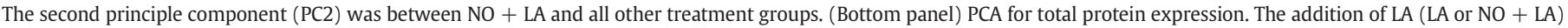

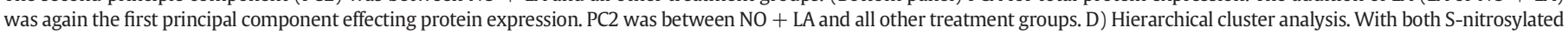
(SNO) and total protein differences LA and NO + LA were clustered together, separate from control and NO which were also clustered together.

effect of LA on 4-HNE and GSH production is mediated through RNS quenching (Fig. 2B and C). In addition, the total NOx level in mitochondrial fraction was markedly elevated after treatment with DETANONOate. Supplement with LA significantly attenuated the elevated amount of NO (Fig. 2D), reaching basal levels. Likewise, the ELISA results showed that cellular carbonyl levels increased by $71 \%$ in mitochondria isolated from NO-treated cells as compared to control cells $(p<0.05)$, whereas addition of LA significantly reduced carbonyl formation (Fig. 2E). Collectively, these data demonstrate that cells treated with NO have increased levels of RNS and ROS, which are opposed by LA supplementation, partially alleviating the stress.

To determine whether the mitochondrial reserve capacity was altered by excess NO and potentially regulated by LA we examined OCR and ECAR in primary aortic endothelial cells and in brain endothelial cells treated with DETA-NONOate with and without LA supplementation. Mitochondrial reserve capacity was determined by uncoupling oxidative phosphorylation with the proton ionophore FCCP, followed by the addition of mitochondrial respiratory-chain complex inhibitors. First, oligomycin $(5 \mu \mathrm{g} / \mathrm{mL})$ was added to all samples to inhibit ATP synthase (complex V), and then FCCP $(5 \mu \mathrm{M})$ was added. Exposure of endothelial cells to FCCP, which uncouples electron flow for ATP synthesis, stimulates respiration to the maximal level and provides an important indicator of mitochondrial reserve capacity (Fig. 3A). Lastly, antimycin A $(40 \mu \mathrm{M})$ was added to inhibit electron flow through complex III, which causes a dramatic suppression of OCR (Fig. 3A). OCR was significantly decreased in cells exposed to NO (106 \pm 11 pmoles/min) compared to OCR basal levels (182 \pm 9 pmoles/min), whereas treatment with LA significantly offset this decline (163 \pm 7 pmoles/min; $p<0.001)$. As indicated in Fig. 3B, after the addition of FCCP, NO induced a 50\% increase in ECAR compared to control $(p<0.01)$ while LA lowered ECAR by $22.5 \%$ $(p<0.05)$. OCR in brain endothelial cells showed comparable values (Fig. 3C), suggesting that the effect of LA on OCR and ECAR is not exclusive to primary-cells.

To determine whether or not LA assists retaining mitochondrial energy production by altering protein $S$-nitrosylation, we examined changes in total protein levels and $S$-nitrosylated proteins by a modified 2D DIGE-based biotin-switch method, in which both the traditional 2D DIGE and the biotin-switch approaches were modified. Each 2D gel contained aliquots labeled for $S$-nitrosylation and total protein from a single sample, and a pooled internal control (Fig. 1). S-nitrosylated

Table 1

S-Nitrosylated proteins that were affected by addition of LA.

\begin{tabular}{lllcc}
\hline Spot no. & Protein identity & Ratio & ANOVA & $\begin{array}{r}\text { Matched } \\
\text { peptides }\end{array}$ \\
\hline 771 & Heat shock cognate 71 kDa protein & -3.0 & 0.043 & 8 \\
880 & Isoform C of Prelamin-A/C & -1.25 & 0.045 & 6 \\
1097 & Protein Prss3 & +3.1 & 0.008 & 23 \\
1104 & Dihydrolipoyllysine & -2.0 & 0.037 & 24 \\
& succinyltransferase of KDC & & \\
1292 & Cytochrome b-c1 complex subunit I & -2.3 & 0.024 & 15 \\
1494 & B-Actin & -2.0 & 0.034 & 16 \\
2031 & Prohibitin & -2.2 & 0.046 & 12 \\
\hline
\end{tabular}

LA: lipoic acid.

KDC: alpha-ketoglutarate dehydrogenase complex. 
Table 2

Proteins that displayed changes in expression affected by LA.

\begin{tabular}{llllc}
\hline Spot no. & Protein identity & Ratio & ANOVA & $\begin{array}{r}\text { Matched } \\
\text { peptides }\end{array}$ \\
\hline 577 & Zyxin & -2.1 & 0.033 & 8 \\
741 & Heat shock 70 kDa protein 5 & -2.6 & 0.025 & 32 \\
1048 & protein disulfide-isomerase & +4.6 & 0.039 & 21 \\
1150 & Vimentin & -3.2 & 0.03 & 36 \\
1319 & Ribonuclease inhibitor isoform a & +1.4 & 0.007 & 6 \\
1327 & Cytochrome b-c1 complex subunit I & +2.0 & 0.026 & 15 \\
\hline
\end{tabular}

LA: lipoic acid.

proteins were recognized utilizing Cy5-maleimide (Cy5-M), and changes in expression levels (total protein) were determined by labeling the proteins with NHS-Cy3. Since maleimide-labeled proteins often display shifts in gel migration due to charge changes, an internal protein control, labeled with NHS-Cy2, was used to normalize total protein expression and determine changes in migration patterns. As expected from the Cy5-M labeling, there was an isoelectric point (pI) shift relative to the same sample labeled for total protein with NHS-Cy3 (Fig. 4, A-D). The resulting images for $S$-nitrosylated proteins and total protein changes were analyzed separately as described previously [29,30].
All the reported results are statistically significant as determined by $p<0.05$. Differential expression analysis revealed that $51 S$-nitrosylated proteins presented expression level changes (Fig. 5A), while total expression levels of 67 of the non $S$-nitrosylated proteins changed (Fig. 5B). Fifteen (27\%) of the 51 differentially $S$-nitrosylated proteins that were affected by NO were subsequently affected by the LA treatment. Of these, two-thirds of the proteins were characterized as having reduced $S$-nitrosylation levels resulting from LA treatment (addition of LA to the cell cultures in the presence of NO; data not shown). Addition of LA alone affected 26 (51\%) of the S-nitrosylated proteins (Fig. 5A). In contrast, 5 (10\%) of the $S$-nitrosylated proteins that resulted from the effects of NO were not affected by LA supplementation (Fig. 5A). From the 67 non-S-nitrosylated proteins displaying altered protein expression levels, 12 proteins (18\%) that were affected by NO were also affected by LA (Fig. 5B); and 37 proteins (56\%) were affected by the LA treatment alone (Fig. 5B). Finally, nine of the proteins (13\%) that were altered by NO, were not affected by LA.

Statistically significant observations were further corroborated by hierarchical cluster analysis and principal component analysis (PCA). Principal component 1 (PC1) for S-nitrosylated proteins (Fig. 5C, top panel), which contains $55.5 \%$ of the variance between samples, confirmed that the addition of LA (LA or NO + LA) is the dominant

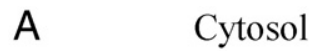

Mitochondria
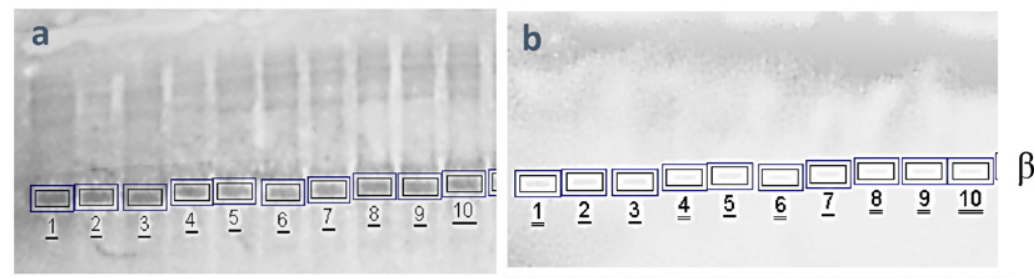

$\beta$-Tubulin

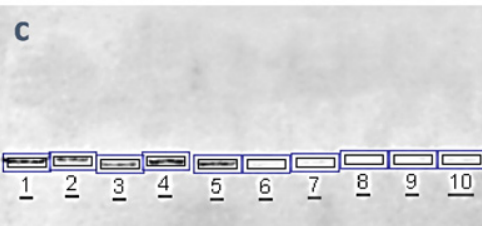

d

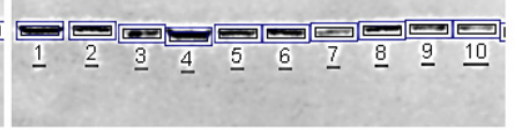

HSP60

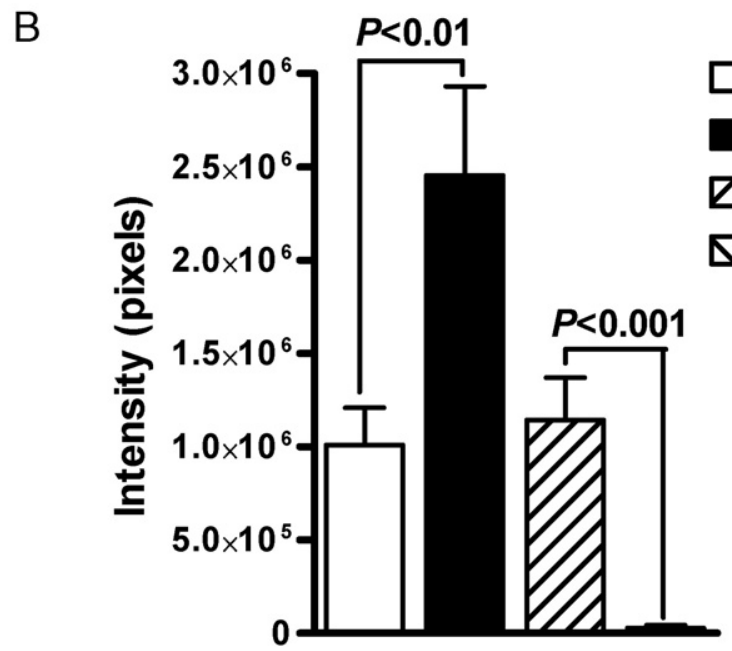

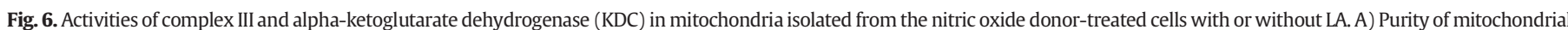

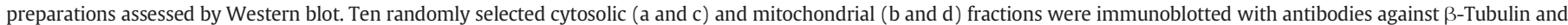

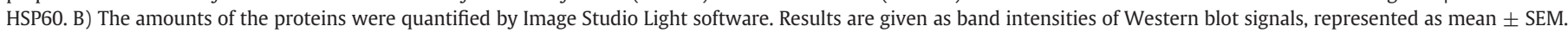

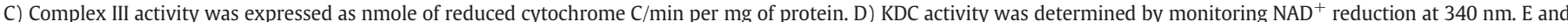

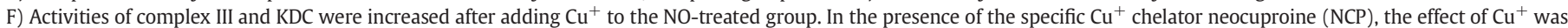

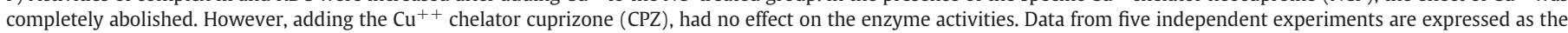
mean \pm SEM. 
C

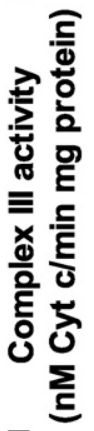

$\mathrm{E}$

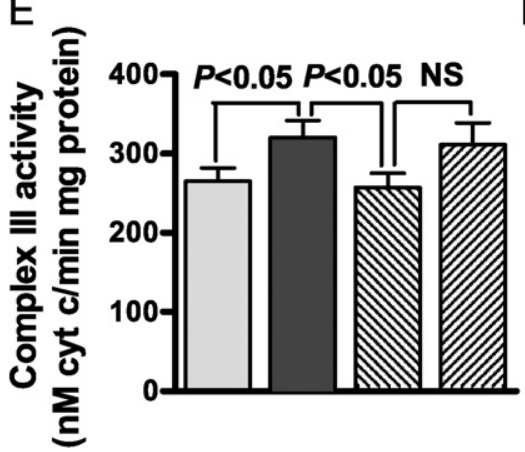

$\mathrm{D}$

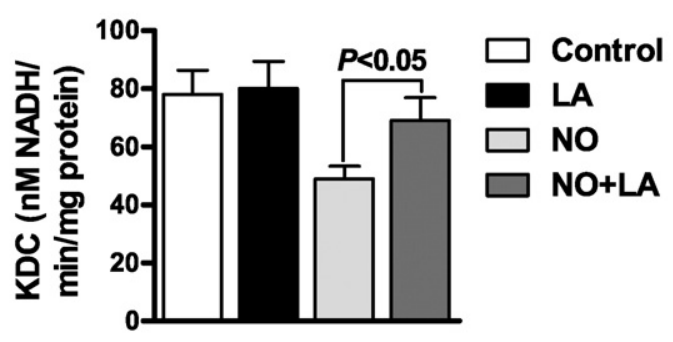

$\mathrm{F}$

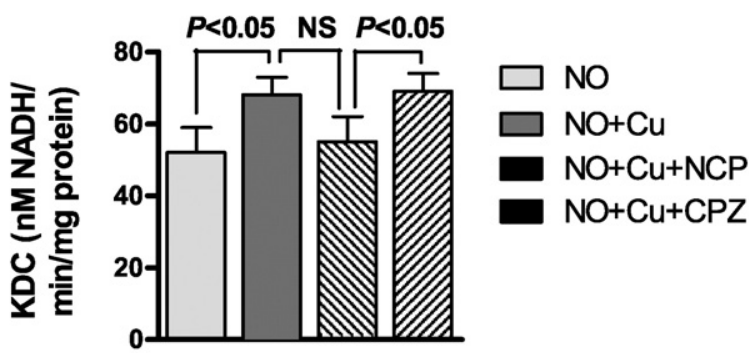

Fig. 6 (continued).

component affecting protein $S$-nitrosylation. On the other hand, PC2, with $24.2 \%$ of variance, is between (NO + LA) and all other treatment groups. For differences in total protein expression, PC1 revealed a similar result with the addition of LA (either LA alone or NO + LA), containing $63.6 \%$ of the variance between samples, confirming that LA was also the dominant component effecting protein alteration (Fig. 5C, bottom panel). PC2 of total protein expression, with $21.3 \%$ of variance, was also between (NO + LA) and all other treatment groups. Similarly, hierarchical cluster analysis (Fig. 5D) revealed that with both $S$-nitrosylation and total protein differences, LA and (NO + LA) were clustered together, and were separated from control and NO. Again, this suggests that the addition of LA was the dominant factor regulating protein $S$ nitrosylation.

Next, seven nitrosylated proteins and six proteins displaying significant changes in expression levels between the NO + LA and the NO groups were identified by MS (Table 1 and Table 2). Among the seven nitrosylated proteins, six proteins treated with (NO + LA) showed decreased $S$-nitrosylation and one protein showed increased $S$ nitrosylation levels at least two-fold above that of NO alone. Interestingly, supplementation of NO-treated cells with LA decreased the nitrosylation of subunit I in complex III by 2.3 -fold, and increased its expression by 2.0 -fold. In addition, LA decreased nitrosylation of dihydrolipoyllysine succinyltransferase by 2.0 -fold, a key component of the enzyme KDC.

\subsection{Complex III and KDC activities}

We found that complex III and KDC, which are primary energy transducting mitochondrial enzymes, are nitrosylated, and that the nitrosylation levels are reduced by adding LA. In order to further evaluate the impact of $S$-nitrosylation by NO and blocking of nitrosylation by LA on the activities of complex III and KDC, we measured their enzymatic activities in mitochondria isolated from aortic endothelial cells. The purity of mitochondrial factions was assessed by Western blot analysis and then quantitated by the Image software after normalization mitochondrial protein concentration to cytosol protein concentration. Mitochondrial and cytosolic fractions were immunoblotted with antibodies against HSP60, a mitochondrial matric protein, and $\beta$-tubulin, a cytosolic protein. The results show that distribution of $\beta$-tubulin was not able to be visualized in the mitochondrial fractions whereas intensity of HSP60 exhibited a marked increase in mitochondrial fractions Fig. 6A and $6 \mathrm{~B}$. The data clearly indicated a good enrichment of mitochondria following the purification. Complex III and KDC activities in the cells treated with the NO donor dropped $25 \%$ and $37 \%$, respectively, whereas LA significantly, restored partially both enzymatic activities $(p<0.05)$ (Fig. 6C and D). To determine whether the alteration of these enzymes' activities could be attributed to $S$-nitrosylation, we added the mitochondrial isolation buffer ( $\mathrm{pH} 7.4)$ containing $\mathrm{CuCl}_{2}(10 \mu \mathrm{M})$ and ascorbic acid $(0.1 \mathrm{mM})$ to isolated mitochondria, followed by incubation at room temperature for $30 \mathrm{~min}$. It is well known that $\mathrm{Cu}^{+}$is a nitrosylating agent $[35,36]$. Ascorbic acid was added to reduce $\mathrm{Cu}^{++}$to $\mathrm{Cu}^{+}$and prevent $\mathrm{Cu}^{+}$spontaneously oxidizing to $\mathrm{Cu}^{++}$. As Fig. $6 \mathrm{E}$ and $\mathrm{F}$ shows, both enzyme activities were augmented after adding $\mathrm{Cu}^{+}$to the NO-treated group. We also found that in the presence of the specific $\mathrm{Cu}^{+}$chelator neocuproine (NCP, $100 \mu \mathrm{M}$ ) the effect of $\mathrm{Cu}^{+}$was completely abolished. However, adding the $\mathrm{Cu}^{++}$chelator cuprizone (bis-cyclohexanoneoxalyldihydrazone, $\mathrm{CPZ}, 100 \mu \mathrm{M}$ ), had no effect (Fig. 6E and 6F). These data show that the enzyme activities are affected by $S$-nitrosylation, likely through $\mathrm{a} \mathrm{Cu}^{+}$-dependent mechanism. By comparing the activity values brought down by adding the NO donor and raised up by adding $\mathrm{Cu}^{+}$, we conclude that $S$-nitrosylation has a major impact in the decline of the enzymatic activities.

\section{Discussion}

In this study, we have demonstrated that a subunit of complex III in the electron transport chain, and dihydrolipoyllysine succinyltransferase, a subunit of KDC in the Krebs cycle, are susceptible to $S$-nitrosylation in response to NO treatment. In addition, $S$-nitrosylation of complex III and KDC coincide with a significant decrease in the activities of these two enzymes. These data demonstrate that $S$-nitrosylation decreases enzyme activities. Although canonical NO signaling occurs likely through its interaction with soluble guanylyl cyclase and controls cyclic guanosine monophosphate (cGMP)-dependent signaling, some investigations 
have suggested that protein S-nitrosation is an essential component of vascular (dys)function [6]. The endothelium is an ideal site for $S$ nitrosylation-dependent signals because endothelial cells constitutively express the NO-producing enzyme endothelial nitric oxide synthase (eNOS), and under inflammatory conditions, it is also exposed to nitric oxide-derived from the inducible NOS isoform (iNOS) [14]. Our findings support these observations. Importantly, our results reveal that LA supplementation significantly reduces $S$-nitrosylation on KDC and complex III, and partially restores their activities as well. These results disclose that regulation of protein $S$-nitrosylation is a novel redox regulatory mechanism of LA by which LA quenches NS to retain normal energy homeostasis. Our results agree with observations by other investigators. For instance, Murphy et al. found that KDC could be nitrosylated and that the nitrosylated form of the enzyme becomes inactive [9]. On the other hand, the fact that LA cannot completely abolish elevated levels of NO and fully restore the enzyme activity suggest that besides protein $S$-nitrosylation, other forms of regulations may exist. For example, cGMP dependent signal pathway and peroxynitrite could be part of these alternative mechanisms. It is well established that some biological activities including regulation of mitochondrial biogenesis [37] by NO are mediated via its primary receptor, the soluble guanylyl cyclase (sGC) [38]. In addition, NO reacts readily with superoxide to produce peroxynitrite, which can inhibit mitochondrial functions. Furthermore, our data show that the impairment of OCAR/ECAR and the mitochondrial reserve capacity after Deta-NONOate administration were readily reversible upon the addition of LA. These observations suggest that this rapid reversible reaction is not likely due to protein $S$-nitrosylation, since covalent modifications are not usually reversible. Since free NO can be converted into SNO and SNO can convert to NO, our current data do not support any effect over the other; i.e., which effect is mediated through free NO released from the NO donor or through S-nitrosylation modification.

We propose that diminished activities of complex III and KDC may lead to the decreased ATP production observed in our experiments for the following reasons: 1) complex III is a critical component of all primary energy transduction systems. It functions in maintaining the proton gradient, which provides $~ 30 \%$ of body energy [39]. 2) KDC is a critical regulatory enzyme in the Krebs cycle [40], limiting the NADH production rate and oxidative phosphorylation [41]. It is thought that KDC plays a key role in bioenergetic deficit associated with oxidative stress [42].3) It is well-established that NO interacts with the mitochondrial respiratory chain by inhibiting cytochrome c oxidase (complex IV) and NADH-ubiquinone oxidoreductase (complex I) [43,44]. And 4) mitochondrial proteins are constantly exposed to excess ROS [45]; therefore, are susceptible to oxidative damage, leading to energy deficiency [46]. Inhibition of mitochondrial complexes in the electron transport chain by excess NO leads to enhanced production of ROS [47]. Our data revealed that levels of 4-HNE-a biomarker of lipid peroxidation [48], carbonylated proteins-a biomarker of protein oxidation [49], and nitric oxide, were significantly increased whereas GSH levels were significantly decreased in the mitochondrial fractions. 4-HNE is derived from peroxidation of n-6 polyunsaturated fatty acids such as arachidonic and linoleic acids and it is one of the most abundant and active lipid peroxides. 4-HNE reacts with amino acids, such as cysteine, lysine or histidine, and forms stable adducts with proteins, leading to modulating activities of proteins. Carbonyl groups (aldehydes and ketones) are produced on protein side chains (especially of Pro, Arg, Lys, and Thr) where they are oxidized and increased. These alterations are partially restored by LA supplementation. The data suggest that LA may provide mitochondrial protection against NO damage, likely through regulation of GSH, a predominantly intra-mitochondrial antioxidant that protects mitochondrial complexes from NO-induced damage [50].

Our proteomics experiments indicate that most of the nitrosylated proteins affected by LA supplementation are involved in protein folding like protein disulfide-isomerase (PDI) and heat shock cognate $71 \mathrm{kDa}$
(Hsc70). LA treatment affected the nitrosylation levels of PDI and Hsc70 by 4.6 -fold increase and 3.0-fold decrease, respectively. PDI contains two thioredoxin domains that catalyze the formation, breakage, and rearrangement of disulfide bonds [51]. Hsc70 is involved in chaperoning unfolded proteins for degradation by both the ubiquitinproteasome system and liposomes [52]. We do not know whether these observations could provide more evidences to support McCarty's hypothesis. He postulated that LA could induce a heat shock response by assisting the formation of intra-molecular disulfide bonds in signaling proteins [53].

We have shown here that the expression of structural proteins including zyxin, prohibitin, vimentin, lamin $\mathrm{A} / \mathrm{C}$ and actin is affected by excess NO, and changed by LA supplementation. We also observed that in response to excess NO, nitrosylation of actin and vimentin increased and appeared to decrease by LA supplementation. Zyxin is a protein attached to the cytoskeleton helping to organize function, dynamics and maintenance of actin fibers [54]. In endothelial cells, zyxin is activated in response to stretch, followed by translocation from the cytoskeleton to the nucleus [55]. Prohibitin (PHB) acts as a mediator of mitochondria shuttling in response to oxidative stress [56]. PHB also acts as a molecular chaperone stabilizing newly synthesized respiratory enzymes in mitochondria [57]. It seems clear that LA exerts multiple regulatory effects beyond direct ROS quenching. These regulatory functions may involve altering protein $S$-nitrosylation and regulation of the expression levels of some proteins that may be affected by $S$-nitrosative mechanisms. Our findings also show that mitochondrial proteins, regardless of their cytosolic or mitochondrial origin, and cytosolic proteins such as zyxin and Hsc70, undergo S-nitrosylation in the presence of elevated NO.

In summary, LA supplementation effectively restores mitochondrial enzyme activities of complex III and the $\alpha$-ketoglutarate dehydrogenase complex inhibited by excess NO, mainly via S-nitrosylation. Regulation of these two enzymes, particularly via reducing $S$-nitrosylation contributes to the protective effect observed. Our studies shed light on a new mechanism of antioxidant activity of LA, and suggest a strategy for the treatment of diseases in which chronic inflammation is involved.

\section{Acknowledgments}

The authors thank Dr. Rosaline Coleman for insightful suggestions and Dr. Carol Parker for critically reviewing the manuscript. This manuscript has been reviewed by the US Environmental Protection Agency, NHEERL and approved for publication. The authors would like to thank Drs. P.R. Kodavanti and J. Royland for their constructive comments. Approval does not signify that the contents reflect the views of the US EPA, nor does mention of trade names or commercial products constitute endorsement or recommendation for use.

This work was supported by the American Heart Association grant \#13GRNT17120056 (to X. Y.).

\section{References}

[1] R.M. Palmer, A.G. Ferrige, S. Moncada, Nitric oxide release accounts for the biological activity of endothelium-derived relaxing factor, Nature 327 (1987) 524-526.

[2] R.M. Palmer, L. Bridge, N.A. Foxwell, S. Moncada, The role of nitric oxide in endothelial cell damage and its inhibition by glucocorticoids, Br. J. Pharmacol. 105 (1992) 11-12

[3] N.M. Iovine, S. Pursnani, A. Voldman, G. Wasserman, M.J. Blaser, et al., Reactive nitrogen species contribute to innate host defense against Campylobacter jejuni, Infect. Immun. 76 (2008) 986-993.

[4] D. Behr-Roussel, A. Rupin, S. Simonet, E. Bonhomme, S. Coumailleau, et al., Effect of chronic treatment with the inducible nitric oxide synthase inhibitor N-iminoethyl-Llysine or with L-arginine on progression of coronary and aortic atherosclerosis in hypercholesterolemic rabbits, Circulation 102 (2000) 1033-1038.

[5] K.M. Cromheeke, M.M. Kockx, G.R. De Meyer, J.M. Bosmans, H. Bult, et al., Inducible nitric oxide synthase colocalizes with signs of lipid oxidation/peroxidation in human atherosclerotic plaques, Cardiovasc. Res. 43 (1999) 744-754.

[6] D.T. Hess, A. Matsumoto, S.O. Kim, H.E. Marshall, J.S. Stamler, Protein S-nitrosylation: purview and parameters, Nat. Rev. Mol. Cell Biol. 6 (2005) 150-166.

[7] S. Moncada, Nitric oxide and cell respiration: physiology and pathology, Verh. K. Acad. Geneeskd. Belg. 62 (2000) 171-179 (discussion 179-181). 
[8] B. Lima, M.T. Forrester, D.T. Hess, J.S. Stamler, S-nitrosylation in cardiovascular signaling, Circ. Res. 106 (2010) 633-646.

[9] J. Sun, E. Murphy, Protein S-nitrosylation and cardioprotection, Circ. Res. 106 (2010) 285-296.

[10] P. Luedike, U.B. Hendgen-Cotta, J. Sobierajski, M. Totzeck, M. Reeh, et al., Cardioprotection through S-nitros(yl)ation of macrophage migration inhibitory factor, Circulation 125 (2012) 1880-1889.

[11] A.R. Diers, K.A. Broniowska, N. Hogg, Nitrosative stress and redox-cycling agents synergize to cause mitochondrial dysfunction and cell death in endothelial cells, Redox Biol. 1 (2013) 1-7

[12] D.B. Cines, E.S. Pollak, C.A. Buck, J. Loscalzo, G.A. Zimmerman, et al., Endothelial cells in physiology and in the pathophysiology of vascular disorders, Blood 91 (1998) 3527-3561.

[13] F. Jiang, G.R. Drummond, G.J. Dusting, Suppression of oxidative stress in the endothelium and vascular wall, Endothelium 11 (2004) 79-88.

[14] O.W. Griffith, D.J. Stuehr, Nitric oxide synthases: properties and catalytic mechanism, Annu. Rev. Physiol. 57 (1995) 707-736.

[15] H.E. Marshall, J.S. Stamler, Nitrosative stress-induced apoptosis through inhibition of NF-kappa B, J. Biol. Chem. 277 (2002) 34223-34228.

[16] J. Qian, D.J. Fulton, Exogenous, but not endogenous nitric oxide inhibits adhesion molecule expression in human endothelial cells, Front. Physiol. 3 (2012) 3.

[17] L. Packer, E.H. Witt, H.J. Tritschler, Alpha-lipoic acid as a biological antioxidant, Free Radic. Biol. Med. 19 (1995) 227-250.

[18] L.J. Reed, From lipoic acid to multi-enzyme complexes, Protein Sci. 7 (1998) 220-224.

[19] O. Tirosh, S. Shilo, A. Aronis, C.K. Sen, Redox regulation of mitochondrial permeability transition: effects of uncoupler, lipoic acid and its positively charged analog LA-plus and selenium, Biofactors 17 (2003) 297-306.

[20] X. Yi, N. Maeda, Endogenous production of lipoic acid is essential for mouse development, Mol. Cell. Biol. 25 (2005) 8387-8392.

[21] Hiller S, DeKroon R, Xu L, Robinette J, Winnik W, et al. Alpha-Lipoic acid protects mitochondrial enzymes and attenuates lipopolysaccharide-induced hypothermia in mice. Free Radic. Biol. Med. 71: 362-367.

[22] A.R. Diers, K.A. Broniowska, V.M. Darley-Usmar, N. Hogg, Differential regulation of metabolism by nitric oxide and S-nitrosothiols in endothelial cells, Am. J. Physiol. Heart Circ. Physiol. 301 (2011) H803-H812.

[23] W.J. Zhang, H. Wei, T. Hagen, B. Frei, Alpha-lipoic acid attenuates LPS-induced inflammatory responses by activating the phosphoinositide 3-kinase/Akt signaling pathway, Proc. Natl. Acad. Sci. U. S. A. 104 (2007) 4077-4082.

[24] K.P. Shay, A.J. Michels, W. Li, A.N. Kong, T.M. Hagen, Cap-independent Nrf2 translation is part of a lipoic acid-stimulated detoxification stress response, Biochim. Biophys. Acta 1823 (2012) 1102-1109.

[25] J.R. Smith, H.V. Thiagaraj, B. Seaver, K.K. Parker, Differential activity of lipoic acid enantiomers in cell culture, J. Herb. Pharmacother. 5 (2005) 43-54.

[26] B.P. Dranka, B.G. Hill, V.M. Darley-Usmar, Mitochondrial reserve capacity in endothelial cells: the impact of nitric oxide and reactive oxygen species, Free Radic. Biol. Med. 48 (2010) 905-914.

[27] D.A. Clayton, G.S. Shadel, Isolation of mitochondria from cells and tissues, Cold Spring Harb. Protoc. 10 (2014) 1109-1111.

[28] M.R. Wieckowski, C. Giorgi, M. Lebiedzinska, J. Duszynski, P. Pinton, Isolation of mitochondria-associated membranes and mitochondria from animal tissues and cells, Nat. Protoc. 4 (2009) 1582-1590.

[29] S.R. Jaffrey, S.H. Snyder, The biotin switch method for the detection of S-nitrosylated proteins, Sci. STKE 2001 (2001) 11.

[30] R.M. DeKroon, J.B. Robinette, C. Osorio, J.S. Jeong, E. Hamlett, et al., Analysis of protein posttranslational modifications using DIGE-based proteomics, Methods Mol. Biol. 854 (2012) 129-143.

[31] R.M. DeKroon, C. Osorio, J.B. Robinette, M. Mocanu, W.M. Winnik, et al., Simultaneous detection of changes in protein expression and oxidative modification as a function of age and APOE genotype, J. Proteome Res. 10 (2011) 1632-1644.

[32] W.M. Winnik, R.M. Dekroon, J.S. Jeong, M. Mocanu, J.B. Robinette, et al., Analysis of proteins using DIGE and MALDI mass spectrometry, Methods Mol. Biol. 854 (2012) 47-66.
[33] A.C. Nulton-Persson, L.I. Szweda, Modulation of mitochondrial function by hydrogen peroxide, J. Biol. Chem. 276 (2001) 23357-23361.

[34] I.A. Trounce, Y.L. Kim, A.S. Jun, D.C. Wallace, Assessment of mitochondrial oxidative phosphorylation in patient muscle biopsies, lymphoblasts, and transmitochondrial cell lines, Methods Enzymol. 264 (1996) 484-509.

[35] H.H. Al-Sa'doni, I.L. Megson, S. Bisland, A.R. Butler, F.W. Flitney, Neocuproine, a selective $\mathrm{Cu}(\mathrm{I})$ chelator, and the relaxation of rat vascular smooth muscle by S-nitrosothiols, Br. J. Pharmacol. 121 (1997) 1047-1050.

[36] R.J. Singh, N. Hogg, J. Joseph, B. Kalyanaraman, Mechanism of nitric oxide release from S-nitrosothiols, J. Biol. Chem. 271 (1996) 18596-18603.

[37] E. Nisoli, E. Clementi, C. Paolucci, V. Cozzi, C. Tonello, et al., Mitochondrial biogenesis in mammals: the role of endogenous nitric oxide, Science 299 (2003) 896-899.

[38] Wobst J, Kessler T, Dang TA, Erdmann J, Schunkert H. Role of sGC-dependent NO signalling and myocardial infarction risk. J. Mol. Med. 93: 383-394.

[39] A.R. Crofts, The cytochrome bc1 complex: function in the context of structure, Annu. Rev. Physiol. 66 (2004) 689-733.

[40] G.J. Cooney, H. Taegtmeyer, E.A. Newsholme, Tricarboxylic acid cycle flux and enzyme activities in the isolated working rat heart, Biochem. J. 200 (1981) 701-703.

[41] L. Tretter, V. Adam-Vizi, Inhibition of Krebs cycle enzymes by hydrogen peroxide: a key role of [alpha]-ketoglutarate dehydrogenase in limiting NADH production under oxidative stress, J. Neurosci. 20 (2000) 8972-8979.

[42] L. Tretter, V. Adam-Vizi, Alpha-ketoglutarate dehydrogenase: a target and generator of oxidative stress, Philos. Trans. R. Soc. Lond. Ser. B Biol. Sci. 360 (2005) 2335-2345.

[43] M. Huttemann, I. Lee, A. Pecinova, P. Pecina, K. Przyklenk, et al., Regulation of oxidative phosphorylation, the mitochondrial membrane potential, and their role in human disease, J. Bioenerg. Biomembr. 40 (2008) 445-456.

[44] J. Zhang, B. Jin, L. Li, E.R. Block, J.M. Patel, Nitric oxide-induced persistent inhibition and nitrosylation of active site cysteine residues of mitochondrial cytochrome-c oxidase in lung endothelial cells, Am. J. Physiol. Cell Physiol. 288 (2005) C840-C849.

[45] E. Barreiro, A.S. Comtois, J. Gea, V.E. Laubach, S.N. Hussain, Protein tyrosine nitration in the ventilatory muscles: role of nitric oxide synthases, Am. J. Respir. Cell Mol. Biol. 26 (2002) 438-446.

[46] N.R. Madamanchi, M.S. Runge, Mitochondrial dysfunction in atherosclerosis, Circ. Res. 100 (2007) 460-473.

[47] A. Musatov, N.C. Robinson, Susceptibility of mitochondrial electron-transport complexes to oxidative damage. Focus on cytochrome c oxidase, Free Radic. Res. 46 (2012) 1313-1326.

[48] X. Zhang, Z. Wang, J. Li, D. Gu, S. Li, et al., Increased 4-hydroxynonenal formation contributes to obesity-related lipolytic activation in adipocytes, PLoS One 8 (2013), e70663.

[49] I. Dalle-Donne, R. Rossi, D. Giustarini, A. Milzani, R. Colombo, Protein carbonyl groups as biomarkers of oxidative stress, Clin. Chim. Acta 329 (2003) 23-38.

[50] D. Brealey, M. Singer, Mitochondrial dysfunction in sepsis, Curr. Infect. Dis. Rep. 5 (2003) 365-371.

[51] T. Pihlajaniemi, T. Helaakoski, K. Tasanen, R. Myllyla, M.L. Huhtala, et al., Molecular cloning of the beta-subunit of human prolyl 4-hydroxylase. This subunit and protein disulphide isomerase are products of the same gene, EMBO J. 6 (1987) 643-649.

[52] E. Meimaridou, S.B. Gooljar, N. Ramnarace, L. Anthonypillai, A.J. Clark, et al., The cytosolic chaperone Hsc70 promotes traffic to the cell surface of intracellular retained melanocortin-4 receptor mutants, Mol. Endocrinol. 25 (2011) 1650-1660.

[53] M.F. McCarty, Versatile cytoprotective activity of lipoic acid may reflect its ability to activate signalling intermediates that trigger the heat-shock and phase II responses, Med. Hypotheses 57 (2001) 313-317.

[54] T. Macalma, J. Otte, M.E. Hensler, S.M. Bockholt, H.A. Louis, et al., Molecular characterization of human zyxin, J. Biol. Chem. 271 (1996) 31470-31478.

[55] S. Suresh Babu, A. Wojtowicz, M. Freichel, L. Birnbaumer, M. Hecker, et al., Mechanism of stretch-induced activation of the mechanotransducer zyxin in vascular cells, Sci. Signal. 5 (2012) ra91.

[56] H. Lee, H. Arnouk, S. Sripathi, P. Chen, R. Zhang, et al., Prohibitin as an oxidative stress biomarker in the eye, Int. J. Biol. Macromol. 47 (2010) 685-690.

[57] L.G. Nijtmans, L. de Jong, M. Artal Sanz, P.J. Coates, J.A. Berden, et al., Prohibitins act as a membrane-bound chaperone for the stabilization of mitochondrial proteins, EMBO J. 19 (2000) 2444-2451. 